\title{
A EFICIÊNCIA JUDICIAL DA JUSTIÇA COMUM ESTADUAL NO BRASIL: UMA ANÁLISE JURIMÉTRICA PELO MÉTODO DEA
}

\author{
THE JUDICIAL EFFICIENCY OF BRAZILIAN COURTS: A JURIMETRIC \\ ANALYSIS BASED ON DEA (DATA ENVELOPMENT ANALYSIS)
}

Martinho Martins Botelho ${ }^{1}$

\section{RESUMO}

O presente artigo trata sobre a utilização de métodos jurimétricos para a avaliação da eficiência da atividade jurisdicional da Justiça Estadual Comum no Brasil, especialmente, sobre a produção de sentenças pelos 27 Tribunais de Justiça (TJs). Procura-se materializar a ideia da eficiência produtiva e alocativa trabalhada na teoria econômica e na Análise Econômica do Direito (AED) por meio do método algébrico da Análise Envoltória de Dados (DEA). A ideia geral é construir indicadores de eficiência para os TJs e rankings de eficiência para 2003 e 2014. Os resultados demonstram que os TJs mais eficientes foram o TJ-PI e o TJ-MG.

Palavras-chave: Eficiência judicial, Jurimetria, Indicadores judiciais

\section{ABSTRACT}

This paper analysis the use of jurimetrical methods for the evaluation of the Brazilian judicial the efficiency of judicial activity, especially the number of sentences on the 27 Brazilians Courts of Justice. We used the idea of productive and allocative efficiency and Economic Analysis of Law based on Data Envelopment Analysis (DEA). The general purpose is to build an efficiency indicator for all Brazilian Courts of Justice and statements efficiency rankings for 2003 and 2014. The results show that Piaui and Minas Gerais Courts are more efficient.

Keywords: Judicial efficiency, Jurimetrics, Judicial index

\footnotetext{
1 Doutorado em Direito pela Universidade de São Paulo - USP, São Paulo, (Brasil). Doutorado em Teoria Econômica pela Universidade Estadual de Maringá - UEM, Paraná, (Brasil). É pesquisador do Núcleo de Estudos Avançados de Direito do Trabalho e Socioeconômico pela Pontifícia Universidade Católica - PUC/PR, Paraná, (Brasil). E-mail: martinho.botelho@yahoo.com.br
} 


\begin{abstract}
"Jurisprudence is primarily an undertaking of rationalism; jurimetrics is an effort to utilize the methods of science in the field of law. The conclusions of jurisprudence are merely debatable; the conclusions of jurimetrics are testable. Jurisprudence cogitates essence and ends and values. Jurimetrics investigates methods of inquiry." (LOEVINGER, 1963.p. 8).
\end{abstract}

\title{
1. INTRODUÇÃO
}

No período recente, o Brasil possui um sistema de administração judiciária bastante peculiar, o qual custa em torno de 1,14\% do Produto Interno Bruto brasileiro em 2014 algo em torno de R\$ 63 bilhões, segundo dados do Ministério do Orçamento, Planejamento e Gestão e do Conselho Nacional de Justiça.

É nesse sentido que se pode passar a questionar: Qual justificativa lógicoquantitativa poderia ser capaz de explicar a eficiência do sistema judicial brasileiro frente a tamanho nível de despesas públicas? Como tal preocupação teórico-empírica poderia ser tratada no âmbito da mensuração da eficiência, inclusive daquela tratada na teoria da Análise Econômica do Direito (AED)?

Essas preocupações têm sido objeto de recente interesse da análise empírica do direito e também da quantificação/medida da eficiência institucional por parte da AED, especialmente quanto se leva em consideração o papel das instituições organizacionais, tais como o Poder Judiciário e a atividade jurisdicional.

O presente artigo assume essa preocupação: a de analisar e mensurar a eficiência judicial no âmbito da atividade jurisdicional de promulgação de sentenças no âmbito cível.

Para tanto, procura-se modelar, estatística e jurimetricamente, os instrumentos da Análise Econômica do Direito (AED) na interpretação dos fenômenos jurídicos, principalmente, da norma jurídica, a partir de elementos teóricos da eficiência produtiva e alocativa. 
A experiência teórica da $\mathrm{AED}$, desde o seu fortalecimento no século $\mathrm{XX}$, caminha para a adoção de modelos de interpretação do fenômeno jurídico, focados principalmente, na noção da eficiência e da racionalidade de decisões (homo oeconomicus).

Visando analisar tal temática, o presente artigo se divide em quatro partes, além da presente Introdução.

$\mathrm{Na}$ primeira parte, foram analisadas as noções fundamentais da concepção da eficiência na Ciência do Direito, especialmente sobre a teoria da Análise Econômica do Direito Judicial. Em seguida, passa-se para a aplicação de modelo jurimétrico, explicitações e avaliação do método algébrico da Análise Envoltória de Dados (DEA, Data Envelopment Analysis). Passa-se, então, para a avaliação dos dados coletados para 27 Tribunais de Justiça no Brasil, e, em seguida, as conclusões a partir da aplicação da técnica jurimétrica no sentido de se medir a eficiência econômica da atividade de gestão da Justiça Estadual Comum brasileira.

Finalmente, passa-se para as discussões e as conclusões.

\section{A CONCEPÇÃO DA EFICIÊNCIA NA CIÊNCIA DO DIREITO}

A eficiência consiste em princípio elencado ao nível constitucional, estando previsto no art. 37 caput da Constituição da República Federativa do Brasil de 1988, inserido pela Emenda Constitucional no 19, de 1998.

Entre os variados ramos do conhecimento que a Ciência Jurídica se apoia para estudar a eficiência judicial (Direito Administrativo, Direito Processual, Direito Constitucional etc.), a Teoria Econômica em especial tem dado uma efetiva contribuição, assim como a própria Jurimetria (BAADE, 1963; LOEVINGER, 1963; BOTELHO, WINTER, 2014) e a Análise Empírica do Direito;

Na seara da Teoria Econômica, possibilita-se a compreensão de como agentes socioeconômicos criam mecanismos racionais de tomada de decisões por meio de critérios de satisfação de amplas necessidades em ambientais de escassez. 
Esse modelo teórico de disponibilidade restrita de recursos em ambientes de escassez foi observado pelo economista inglês Lionel Robbins, sendo que tal abordagem teórica vem contribuindo par ao estudo de decisões judiciais em recursos limitados e com amplas possibilidades decisórias, tal como acontece na atividade jurisdicional em geral.

Destarte, a razão teleológica da Teoria da Análise Econômica do Direito Processual vem se pautando na possibilidade de estudos da distribuição eficiente da justiça, de acordo com os mesmos critérios de eficiência alocativa e distributiva de recursos na sociedade em geral.

Na visão de Richard Allen Posner (2000, p. 33), as noções de justiça incluem algo mais do que a eficiência. Nesse sentido, acaba sendo ineficiente a tolerância aos acordos suicidas, à discriminação privada pela origem racional, religiosa ou sexual, entre outros.

A justiça representaria uma noção mais ampla do que a economia, mesmo que a Teoria Econômica possa esclarecer temas sobre a existência de valores para a sociedade, tal como apontado no ideal econômico de justiça.

A fundamentação existencial da Teoria Econômica pode ser a compreensão do comportamento dos agentes socioeconômicos, criando-se um modelo teórico que permite o entendimento das variáveis levadas em consideração na tomada de decisões voltadas para uma finalidade qualquer. Assim, a atividade econômica consiste naquela ação social voltada para a escola do urso de recursos, com a finalidade de atender as necessidades sócio-humanas, ou a gestão de recursos escassos (NUSDEO, 2008, p. 28).

Com isso, a Teoria Econômica e a Teoria Jurídica vêm, nas últimas décadas, tentando se compatibilizar no sentido de acompanharem a relação entre eficiência e justiça, a partir da limitação do que possa ser possível com uma e com outra, estabelecendo novas fronteiras no estudo da consequência socioeconômica da norma jurídica (SALAMA, 2008, p. $55)$.

A Teoria Econômica e a AED permitem a previsão das consequências de determinada atividade jurisdicional com mais coerência lógica e, assim, com amplo instrumental analítico disponível para o jurista, voltando-se para o conhecimento do entorno jurisdicional, econômico e social. 


\subsection{A EFICIÊNCIA ECONÔMICA COMO VALOR JURÍDICO}

A noção de eficiência econômica, tal como já fora explanado, passa pela ideia do economista e sociólogo Vilfredo Pareto, que entendia que uma mudança socioeconômica seria considerada eficiente quando o novo cenário produzisse um produto superior ao status quo ante, sem que ocorressem perdas para nenhum dos atores socioeconômicos envolvidos (COASE, 1960, p. 2).

Com isso, poderia se dizer que haveria uma melhoria de Pareto, quando ao menos um agente auferisse ganhos sem que outros apresentassem perdas.

Em uma situação na qual os agentes ganhem sem significar a perda para qualquer outro, haveria o Ótimo de Pareto.

São vários os casos que podem ser visualizados sob a ótica da eficiência econômica (ou socioeconômica). Pode-se citar: o problema da distribuição de renda pela tributação, a realocação de recursos por meio de contratos, o papel do Estado na propriedade privada etc.

Assim, o sistema jurídico arquitetará movimentações na alocação de recursos na sociedade, através de elementos econômicos, morais, políticos, entre outros. E, nesse contexto, haverá de se questionar: quais seriam os mecanismos eficientes em Pareto?

Além da eficiência econômica do tipo paretiana, existe o conceito de eficiência de Kaldor-Hicks, por meio do qual se visualizam ganhos sociais maiores do que perdas individuais globais, por meio de um sistema de compensação social.

Os dois modelos teóricos de eficiência também passam pela discussão sobre a eficiência como elemento teológico do direito. É o que será visto a seguir.

\subsection{A EFICIÊNCIA COMO ELEMENTO TELEOLÓGICO DO DIREITO}

Ao se indagar sobre a razão existencial do Direito, efetivamente, fala-se em valores políticos, religiosos e também econômicos (SALDANHA, 2004, p. 25 e 26). 
Esses valores são construídos para as instituições sociais, sendo que, na teoria da Análise Econômica do Direito, o direito costuma ser dividido em dois tempos: a elaboração da norma (ex ante) e a aplicação da norma (ex post) (COOTER, ULEN, 2008, p. 54).

No tempo ex ante, a escolha de valores sem parâmetros jurídicos é feito anteriormente, também podendo ser fundamentada em referências anteriores, tal como ocorre normalmente em processos constituintes derivados, mecanismo de legislação ordinária, regulamentações administrativas etc.

A elaboração da norma representa um relevante espaço na cognição dos seus valores, em razão da sua construção por valores culturais, morais, psicológicos, entre outros.

A mesma ideia pode ser construída para o momento ex post do direito. No entanto, na posição ex post, é dado ao aplicador do direito um limite menor na exegese jurídica e no ato criativo de argumentação.

Com isso, para a AED, o Estado teria a finalidade de atingir algumas metas valorativas, seja no momento ex ante ou no momento ex post da norma. E, em tais momentos, o vetor influenciador fundamental seria a eficiência no sentido paretiano ou no sentido kaldorhicksiano.

A teoria da AED se envolve com as razões teleológicas do direito no sentido de proporcionar aos juristas mecanismos de melhor conhecer os fatos e, assim, decidir de acordo com mecanismos menos onerosos para a sociedade.

\subsection{AS BASES FUNDAMENTAIS DA APLICAÇÃO DA AED NA CIÊNCIA JURÍDICA}

As bases fundamentais da AED incluem a compreensão da questão do homo oeconomicus e a racionalidade na tomada de decisões.

Em função da necessidade da tomada de decisões, um agente socioeconômico encontra um dilema (tradeoff) na sua existência: o da satisfação das suas amplas necessidades em um ambiente de escassez de recursos. Tal dilema acaba exigindo uma escolha racional, uma decisão, a partir da qual tal agente estipulará prioridades, já que procurará, entre 
alternativas, uma que propicie uma melhor satisfação dos seus desejos (ilimitados). (RODRIGUES, 2007, p. 31).

$\mathrm{Na}$ teoria microeconômica, os agentes socioeconômicos estão envolvidos na necessidade de maximizar a utilidade das suas decisões sob as condições já mencionadas, sendo tal elemento epistemológico concebido como homo oeconomicus, conforme as ideias do economista Lionel Robbins (HASTIE, DAWES, 2001, p. 11).

Assim, o indivíduo racional, homo oeconomicus, tomaria as suas decisões de acordo com a relação custo-benefício, preferindo alternativas cujos benefícios fossem superiores aos seus custos (RODRIGUES, 2007, p. 13).

Com isso, visualiza-se um mecanismo individual de maximização racional da utilidade, a partir do qual os indivíduos realizam escolhas que procuram atender aos seus interesses pessoais, às suas preferências pessoais.

Antes do pensamento de Lionel Robbins, a Escola Neoclássica ou Marginalista entendia que o processo de decisões era feito através da aferição dos benefícios e dos seus custos a partir da realização do acréscimo variacional da próxima unidade, certamente, influenciada pela lógica newtoniana mecanicista da época (SALAMA, 2008, p. 52).

Tal lógica baseada em elementos éticos da eficiência econômica nortearia as decisões mais inusitadas e inclusive do fenômeno jurídico. Na visão da AED, as decisões dos agentes socioeconômicos em um ambiente diversificado envolveria uma análise custobenefício, e inclusive no mundo jurídico (MARINHO, 2005, p. 34).

Assim, decisões que parecem irracionais ganham a conotação de racionais, tendo em vista a necessidade intrínseca do ser humano avaliar o seu processo de escolha a partir de diversos valores.

Tais decisões, na média, são voltadas para a maximização de interesses individuais em um processo de escolha em conjuntura de escassez. 


\section{INSTRUMENTOS E MÉTODO JURIMÉTRICO APLICADO}

Nesta seção, estão apresentadas as técnicas jurimétricas da Análise Envoltória de Dados (Data Envelopment Analysis) além da fonte de dados do estudo e das variáveis insumo (input) e produto (output) escolhidas para a análise feita para a Justiça Estadual Comum brasileira, para o período 2003-2014.

A metodologia DEA consiste em conjunto teórico não-paramétrico que busca construir as fronteiras de eficiência por meio da base teórica algébrica da programação linear, sendo desnecessária a especificação de relações em forma de função matemática, entre as variáveis insumo e produto utilizados, no caso, na gestão do Poder Judiciário estadual brasileiro (VIEIRA, 2003, p. 979; BOTELHO, WINTER, 2014).

A DEA indica a eficiência com a qual cada unidade de produção (ou Unidade Tomadora de Decisão, Decision Making Units, DMUs) transforma os insumos em produtos, na comparação com outras unidades consideradas.

Para o presente caso, as DMUs são consideradas como os 27 Tribunais de Justiça (TJs) dos Estados e do Distrito Federal. Os insumos considerados foram aqueles relacionados com os gastos em recursos humanos e os gastos com bens e serviços. O produto dos TJs é determinado no formato de um serviço jurisdicional específico: a quantidade de sentenças proferidas.

Originalmente, o modelo DEA fora desenvolvido por Charnes, Cooper e Banker (1978) a partir da hipótese de retorno constantes de escala (modelo CCR ou CRS, constant return to scale) e, em seguida, fora incrementado por Banker, Charnes e Cooper (1985) com a possibilidade de retorno variável de escala (modelo BCC ou VRS, variable return to scale).

No caso do modelo VRS, os fatores de escala da produção são classificados como:

a) Retornos crescentes de escala, quando as DMUs trabalham com baixos valores de insumos (inputs);

b) Retornos decrescentes de escala, quando as DMUs trabalham com elevados valores de insumos (inputs); 
c) Retornos constantes, quando ocorre uma transição dos retornos crescentes de escala para os retornos decrescentes de escala.

A análise empírica da eficiência alocativa por meio da Análise Envoltória de Dados DEA, Data Envelopment Analysis) é, sem dúvida, a técnica mais conhecida, sendo definida por problemas de programação linear, funcionando bem quando os desvios em relação à produção ótima são consequências apenas de ineficiências técnicas de unidades produtivas.

A Análise Envoltória de Dados objetiva a determinação do cálculo da eficiência de unidades de produção (conhecidas por DMUs, Decision Making Units, ou Unidades de Tomada de Decisão), a partir da quantidade ou nível de recursos produtivos empregados (insumos ou inputs) e de resultados produtivos alcançados (produtos ou outputs), tal como demonstrado na figura 1.

Com a determinação do cálculo da eficiência de cada DMU em um processo produtivo, torna-se possível também a verificação das unidades mais eficientes e as menos ineficientes, induzindo-se uma comparação. As DMUs consideradas eficientes serão aquelas situadas na fronteira de eficiência alocativas, e as DMUs ineficientes são aquelas situadas abaixo da fronteira de eficiência já calculada (FARE, GROSSKOPF, LOVELL, 1994, p. 17).

Além disso, o método DEA possibilita a indicação do nível de ineficiência no sentido de se elaborarem metas (targets) ótimas de produção e de consumo, alocação eficiente, a partir de dados amostrais observados em casos de eficiência e com a facilidade de não se impor alguma tecnologia arbitrária a priori.

Outrossim, a DEA permite a inferência da natureza dos retornos de escala para cada DMU, obtendo-se, assim, cada DMU ineficiente, e que seriam referências (peers) cujas combinações indicariam a situação da fronteira eficiente de produção.

A DEA otimiza cada observação individual, de tal maneira que é possível estimar uma fronteira eficiente composta por DMUs que detêm as melhores decisões alocativas dentro da amostra em avaliação (utilidades Pareto-eficientes).

Com isso, essas unidades de produção auxiliam no benchmark para o conjunto de DMUs ineficientes. 
FIGURA 1 - ESTRUTURA DE UM PROCESSO PRODUTIVO SIMPLES (INSUMOPRODUTO)

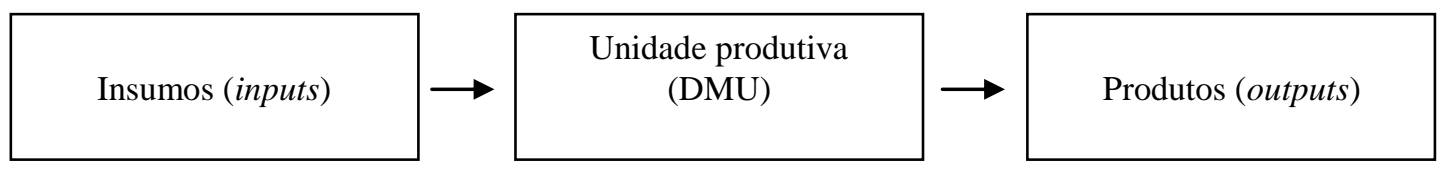

Fonte: Elaboração própria, 2016.

Um conjunto de DMUs deve ter a mesma utilização de inputs e de outputs, devendo ser homogêneo, ou seja, as DMUs devem ser de categorias e natureza semelhante e elas devem ter autonomia na tomada de decisão.

No âmbito da DEA, A eficiência consiste, genericamente, na razão da soma ponderada de outputs ponderada pelos inputs necessários para gerar a produção. Em outras palavras, na fronteira de eficiência, estarão as DMUs cuja quantidade máxima de produção foi realizada por meio dos insumos utilizados (BOUERI, 2015, p. 270).

Os pesos utilizados nas ponderações mencionadas e obtidos em DEA são obtidos por fundamentos de programação linear, atribuindo-se para cada DMU os pesos que maximizam a eficiência produtiva.

A vantagem da utilização da DEA em comparação com outros modelos de análise de produção é a sua capacidade de incluir múltiplos insumos (entradas, fatores de produção, inputs, recursos) e múltiplos produtos (outputs, saídas) para a determinação de uma medida de eficiência única, com ou sem a inclusão de julgamentos subjetivos pelos decisores.

Do ponto de vista tipológico, existem dois modelos principais de DEA utilizados na análise de um processo produtivo: o CCR e o BCC (LOVELL, 1994, p. 176).

O modelo DEA-CCR foi idealizado por Charnes, Cooper e Banker (1978) permite retornos constantes de escala e assume proporcionalidade entre inputs e outputs. ${ }^{2}$

O modelo DEA-BCC foi idealizado por Banker, Charnes e Cooper (1985) caracteriza-se pelos retornos variáveis à escala, substituindo o axioma da proporcionalidade pelo axioma da convexidade. ${ }^{3}$ 
Para tais modelos, são possíveis duas orientações radiais na procura pela fronteira de eficiência (COELLI, 1994):

i) Orientação a inputs, quando se deseja minimizar os recursos disponíveis, sem alteração do grau de produção; e

ii) Orientação a outputs, quando a finalidade é aumentar a quantidade de produção, sem modificar as quantidades dos recursos usados.

O que se sugere para o presente estudo empírico da Administração Judiciária é a adoção de modelos de eficiência orientados para os produtos (outputs), ou seja, para a maximização das sentenças prolatadas sem diminuir os insumos (os gastos com recursos humanos e os gastos com bens e serviços), porque os gestores do Poder Judiciário no Brasil buscam a expansão dos recursos financeiros disponíveis e da quantidade de sentenças judiciais.

\section{FONTE DE DADOS E ESCOLHA DO MODELO}

A amostra da pesquisa foi construída a partir das 27 unidades federativas brasileiras, Poder Judiciário Comum dos Estados e do Distrito Federal que atual na distribuição de serviços jurisdicionais. Nos modelos DEA, esses Tribunais de Justiça Estaduais são denominado s DMU, os quais passam a ser avaliados como eficientes ou ineficientes.

Os anos de referência utilizados na pesquisa foram doze anos (2003-2014), por se tratarem de períodos antes e depois da Emenda Constitucional n ${ }^{\circ} 45$, de 2004; a qual instituiu a Reforma no Judiciário brasileiro, principalmente, com a criação do Conselho Nacional de Justiça (CNJ), o qual foi complementado, posteriormente, pela implementação da tecnologia (processo eletrônico) e pela tentativa de fomento da cultura do diálogo e do consenso na sociedade.

\footnotetext{
${ }^{2}$ Visivelmente, trata-se da sigla dos sobrenomes dos seus criadores. Também é conhecido pela sigla CRS, Constant Returns to Scale.

3 Trata-se da sigla dos sobrenomes dos criados do modelo. Também é conhecida pela sigla VRS, Variable Returns to Scale.
} 
O critério de seleção da amostra estatística foi a realização de gastos judiciários com fatores de produção em cada judiciário estadual e distrital no sistema jurisdicional comum e a disponibilidade completa de informações.

Não se exclui nenhum Estado por conta da disponibilidade dos dados de input e de output no período analisado.

Levando-se em consideração o modelo proposto sobre eficiência judicial, os inputs e o output utilizados foram os seguintes:

a) Inputs: foram definidos como as despesas com recursos humanos (drh_e) e as despesas com bens e serviços (dbs_e) no sistema judicial estadual (por Estado e pelo Distrito Federal). O somatório dos dois itens compõe a despesa total do Poder Judiciário estadual e distrital no período analisado.

b) Output: foi determinado como a quantidade de sentenças judiciais proferidas por cada TJ (sent_e).

A coleta de dados foi realizada a partir dos doze relatórios anuais do $\mathrm{CNJ}$, estando disponibilizados no portal da entidade (www.cnj.jus.br).

Os dados utilizados na pesquisa foram coletados nos meses de janeiro e de fevereiro de 2016. Ressalte-se ainda que o CNJ tem informações sobre as despesas em moeda corrente e também a quantidade de servidores e de magistrados.

Para que a metodologia DEA seja aplicada, utilizou-se os softwares Microsoft Excel 2010, LibreOffice 4.4 e Stata 13da StataCorp LP.

\section{RESULTADOS}

Na tabela 1, verifica-se que, em média, no ano de 2003, os 27 TJs gastaram com recursos humanos, e com bens e serviços o equivalente a $\mathrm{R} \$ 341$ milhões e a $\mathrm{R} \$ 56,1$ milhões, respectivamente. As despesas totais médias dos TJs foram de R \$ 397,1 milhões. 
Ao se comparar a média de despesas de 2014 (tabela 2) com a média de 2003 (tabela 1), verifica-se um crescimento do valor médio de $263,64 \%$ para os gastos com recursos humanos; $149,55 \%$ para as despesas com bens e serviços. Tem-se também que a quantidade de sentenças prolatadas nos TJs, em média, apresentou uma tendência ascendente, passando de aproximadamente 178.000, em 2003, para 455.000 aproximadamente em 2014, representando uma expansão de $155 \%$ aproximadamente.

TABELA 1 - Estatísticas descritivas das variáveis consideradas na mensuração da eficiência dos 27 Tribunais Estaduais e do Distrito Federal, 2003

\begin{tabular}{|c|c|c|c|c|c|c|c|}
\hline Variável & Observacões & Média & Mediana & Mínimo & Máximo & $\begin{array}{l}\text { Desvio- } \\
\text { padrão }\end{array}$ & Variância \\
\hline drh_e & 27 & $3.41 \mathrm{E}+08$ & $1.62 \mathrm{E}+08$ & $2.29 \mathrm{E}+07$ & $2.47 \mathrm{E}+09$ & $5.02 \mathrm{E}+08$ & $2.52 \mathrm{E}+17$ \\
\hline dbs_e & 27 & $5.61 \mathrm{E}+07$ & $2.86 \mathrm{E}+07$ & 5190046 & $2.57 \mathrm{E}+08$ & $6.87 \mathrm{E}+07$ & $4.72 \mathrm{E}+15$ \\
\hline sent_e & 27 & 178269.4 & 125498 & 2146 & 865197 & 206310.3 & $4.26 \mathrm{E}+10$ \\
\hline
\end{tabular}

Obs: drh_e: gastos com recursos humanos; dbs_e: gastos com bens e serviços; sent_e: quantidade de sentenças proferidas pelo Tribunal.

Fonte: Elaboração própria conforme dados do CNJ, 2016.

TABELA 2 - Estatísticas descritivas das variáveis consideradas na mensuração da eficiência dos 27 Tribunais Estaduais e do Distrito Federal, 2014

\begin{tabular}{|c|c|c|c|c|c|c|c|}
\hline Variável & Observacões & Média & Mediana & Mínimo & Máximo & $\begin{array}{l}\text { Desvio- } \\
\text { padrão }\end{array}$ & Variância \\
\hline drh_e & 27 & $1.24 \mathrm{E}+09$ & $7.66 \mathrm{E}+08$ & $1.32 \mathrm{E}+08$ & $7.39 \mathrm{E}+09$ & $1.52 \mathrm{E}+09$ & $2.30 \mathrm{E}+18$ \\
\hline dbs_e & 27 & $1.40 \mathrm{E}+08$ & $7.08 \mathrm{E}+07$ & 407172.6 & $7.68 \mathrm{E}+08$ & $1.91 \mathrm{E}+08$ & $3.64 \mathrm{E}+16$ \\
\hline sent_e & 27 & 455827 & 193003 & 34742 & 3721890 & 727381.4 & $5.29 \mathrm{E}+11$ \\
\hline
\end{tabular}

Obs: drh_e: gastos com recursos humanos; dbs_e: gastos com bens e serviços; sent_e: quantidade de sentenças proferidas pelo Tribunal.

Fonte: Elaboração própria conforme dados do CNJ, 2016.

Nas Tabelas 3 e 4, são apresentados os coeficientes de correlação entre os inputs e o output sendo identificada baixa correlação serial, razão pela qual se optou em mantê-los.

TABELA 3 - Correlações entre os inputs, 2003

\begin{tabular}{|cccc|}
\hline & drh_e & dbs_e & sent_e \\
drh_e & 1.0000 & & \\
dbs_e & 0.8172 & 1.0000 & 1.0000 \\
sent_e & 0.5132 & 0.5933 & \\
\hline
\end{tabular}

Fonte: Elaboração própria conforme resultados do Stata/MP 13, 2016. 
Na tabela 5, estão apresentados os escores de eficiência dos 27 TJs brasileiros na atividade jurisdicional de prolação de sentenças judiciais a partir de gastos do Poder Judiciário em recursos humanos, e bens e serviços para os anos de 2003 e 2014.

Em 2003, observa-se que seis TJs estavam localizados na fronteira de eficiência, ou seja, com o $\theta=1$ (escore $=1$ ). Tais TJs foram apontados como eficientes na maximização da quantidade de sentenças proferidas. Eram os TJs de: Minas Gerais, Mato Grosso, Rio Grande do Sul, Santa Catarina, Tocantins e Piauí. Por sua vez, vinte e dois TJs ficaram abaixo dessa fronteira. Além disso, verifica-se que, desses 22 TJs, o TJ-AM apresentou o pior resultado entre os ineficientes.

TABELA 4 - Correlações entre os inputs, 2014

\begin{tabular}{|cccc|}
\hline & drh_e & dbs_e & sent_e \\
drh_e & 1.0000 & & \\
dbs_e & 0.8668 & 1.0000 & 1.0000 \\
\hline sent_e & 0.9636 & 0.8841 & \\
\hline
\end{tabular}

Fonte: Elaboração própria conforme resultados do Stata/MP 13, 2016.

No ano de 2014, já com a presença de controle por parte do CNJ e implementação de sistemas de processo eletrônico, ocorreu uma mudança de fronteira de eficiência do sistema judicial, sendo que sete TJs se tornaram eficientes, com destaques para os TJs de: Bahia, Minas Gerais, Piauí, Paraná, São Paulo, Alagoas e Sergipe. A quantidade de TJs ineficientes tornou-se menor, correspondendo a vinte. Os TJs de Mato Grosso, Rio Grande do Sul, Santa Catarina e Tocantins deixaram a fronteira de eficiência $(\theta=1)$, atingindo os patamares de eficiência de 0.51832, 0.833806, 0.884374, e 0.628351, respectivamente. Os TJs do Amapá, do Maranhão e do Rio Grande do Norte foram os que tiveram os piores resultados comparativamente entre os anos estudados. Curiosamente, o TJ do Distrito Federal resultou no pior índice de eficiência, sendo o seu escore de 0.346644 em 2014. Os TJs de Minas Gerais e do Piauí permaneceram na fronteira de eficiência, com o escore igual a 1.

Ainda nas tabelas 1 e 2, percebe-se que 17 TJs (Acre, Amapá, Amazonas, Ceará, Distrito Federal, Espírito Santo, Goiás, Maranhão, Mato Grosso do Sul, Pará, Paraíba, Pernambuco, Rio de Janeiro, Rio Grande do Norte, Rondônia, Roraima) estiveram abaixo da fronteira de eficiência nos dois períodos. Os TJs de Alagoas, Bahia, Mato Grosso, Paraná, Rio 
Grande do Sul, Santa Catarina, São Paulo, Sergipe e Tocantins variaram a sua posição entre a fronteira e abaixo dela.

TABELA 5 - Escores de eficiência dos 27 Tribunais de Justiça dos Estados e do Distrito Federal, 2003 e 2014 2003

Tribunal de

\begin{tabular}{|c|c|c|c|c|c|}
\hline Rank & $\begin{array}{c}\text { Tribunal de } \\
\text { Justica }\end{array}$ & Escore ( $\theta)$ & Rank & $\begin{array}{c}\text { Tribunal de } \\
\text { Justica } \\
\end{array}$ & Escore $(\theta)$ \\
\hline 1 & Minas Gerais & 1 & 1 & Bahia & 1 \\
\hline 1 & Mato Grosso & 1 & 1 & Minas Gerais & 1 \\
\hline 1 & Rio Grande do Sul & 1 & 1 & Piauí & 1 \\
\hline 1 & Santa Catarina & 1 & 1 & Paraná & 1 \\
\hline 1 & Tocantins & 1 & 1 & São Paulo & 1 \\
\hline 6 & Piauí & 1 & 6 & Alagoas & 1 \\
\hline 7 & Paraíba & 0.878455 & 7 & Sergipe & 1 \\
\hline 8 & Paraná & 0.825413 & 8 & Goiás & 0.978942 \\
\hline 9 & Rondônia & 0.81146 & 9 & Santa Catarina & 0.884374 \\
\hline 10 & Mato Grosso do Sul & 0.711498 & 10 & Rio Grande do Sul & 0.833806 \\
\hline 11 & Sergipe & 0.735163 & 11 & Pará & 0.799918 \\
\hline 12 & Goiás & 0.598205 & 12 & Rondônia & 0.77584 \\
\hline 13 & Distrito Federal & 0.582922 & 13 & Ceará & 0.775096 \\
\hline 14 & Bahia & 0.550918 & 14 & Paraíba & 0.77412 \\
\hline 15 & Espírito Santo & 0.520911 & 15 & Rio de Janeiro & 0.772154 \\
\hline 16 & Alagoas & 0.442295 & 16 & Mato Grosso do Sul & 0.770594 \\
\hline 17 & Rio de Janeiro & 0.439666 & 17 & Acre & 0.744994 \\
\hline 18 & Acre & 0.405791 & 18 & Pernambuco & 0.703907 \\
\hline 19 & Pernambuco & 0.40353 & 19 & Espírito Santo & 0.670701 \\
\hline 20 & Roraima & 0.332849 & 20 & Tocantins & 0.628351 \\
\hline 21 & São Paulo & 0.308471 & 21 & Amazonas & 0.608774 \\
\hline 22 & Maranhão & 0.261727 & 22 & Amapá & 0.596427 \\
\hline 23 & Pará & 0.236768 & 23 & Roraima & 0.587596 \\
\hline 24 & Rio Grande do Norte & 0.209413 & 24 & Mato Grosso & 0.51832 \\
\hline 25 & Amapá & 0.180385 & 25 & Maranhão & 0.478359 \\
\hline 26 & Ceará & 0.156739 & 26 & Rio Grande do Norte & 0.384427 \\
\hline 27 & Amazonas & 0.014141 & 27 & Distrito Federal & 0.346644 \\
\hline
\end{tabular}

Fonte: Elaboração própria conforme os resultados, 2016.

No condizente às causas da ineficiência, em um primeiro momento, pode-se elencar: as diferenças de realidades das Justiças Estaduais, inclusive daquelas que ficaram abaixo da fronteira de eficiência. Assim, a determinação da ineficiência pelo lado de excesso de gastos em recursos humanos ou em bens e serviços, ou a escassez de sentenças prolatadas, 
no modelo jurimétrico apresentado, não pode ser determinado como fator de ineficiência para os dois períodos.

Para tal determinação, jurimetricamente, é possível inferir por meio de outros métodos como o Índice de Malmquist (e a sua decomposição em emparelhamento, e deslocamento de fronteira de eficiência), o que não é o propósito da presente pesquisa, podendo ser analisada em outras investigações.

\section{DISCUSSÃO DOS RESULTADOS}

Os resultados da presente pesquisa sugerem que a atividade jurisdicional da prolação de sentenças tem-se apresentado com alguma variabilidade entre as Justiças Estaduais e do Distrito Federal, tendo em vista os elevados desvios-padrão determinam disparidades na gestão dos recursos aplicados pelos Tribunais de Justiça.

$\mathrm{Na}$ atualidade, não existem regiões mais eficientes na utilização de recursos para atividades de sentenças judiciais.

De acordo com os resultados dos escores de eficiência de cada TJ, pode-se afirmar que houve uma mudança na fronteira de eficiência de 2003 para 2014. Ademais, percebe-se uma elevada disparidade entre os TJs menos eficientes para os dois períodos. Enquanto em 2003, o TJ-AM apresentou um escore $(\theta=0.014141)$ baixíssimo; em 2014, o TJ-DF fora o menos eficiente, apresentando um escore de 0.346644 .

Para o caso de alguns TJs, é o caso de se investigar a razão de escores tão baixos, segundo o método DEA, sugerindo-se inclusive a implantação de um índice de produtividade.

As alterações dos escores e a dinâmica dos ranks de classificação de eficiência mostram que, após mudanças institucionais implementadas pelo CNJ (EC n⿳ 45, de 2004; e metas), a maioria dos TJS apresentaram significativo avanço na eficiência ao longo do tempo. Assim mesmo, o próprio CNJ procura busca a melhoria contínua no aparato jurisdicional do sistema judicial, sendo persistentes problemas de gestão e de gerenciamento do setor. 
A atividade jurisdicional no Brasil ainda procura pelo valor da eficiência, principalmente no condizente ao seu insumo principal: as sentenças judiciais.

\section{CONSIDERAÇÕES FINAIS}

A título de considerações finais, desde a sua constituição pela EC no 45/2004, o Conselho Nacional de Justiça vem perseguindo a construção de metas e de relatórios que possibilitem o diagnóstico do Poder Judiciário.

Fala-se em indicadores do tipo "taxa de congestionamento", segurança jurídica e certeza aos negócios jurídicos, a duração razoável do processo e a eficiência ainda vem sendo um dos princípios amplamente discutidos no âmbito do CNJ.

Não obstante, ainda parece estar longe a composição de um Poder Judiciário eficiente, justamente em função de uma crise do Direito e até mesmo de uma crise do Estado. Variadas são as causas do problema.

O incremento vertiginoso da litigiosidade após a Constituição Federal de 1998 e de diversos diplomas legais ainda representam uma das razões da saturação de litígios, sendo uma das origens da questão da ineficiência judicial brasileira.

No entanto, outras razões também podem ser elencadas para a morosidade, os elevados custos processuais e a saturação de processos judiciais, com alta carga de financiamento do Poder Judiciário pelas contas públicas, tais como:

a) a ausência de adequadas condições de trabalho para os magistrados;

b) o desequilíbrio na distribuição dos recursos humanos;

c) a baixa qualificação de servidores que atuam no Poder Judiciário;

d) a ausência do compromisso por produtividade e eficiência.

A análise dos TJs na presente pesquisa revela que as unidades jurisdicionais estatais contêm diferentes resultados. 
Mesmo que o conceito de celeridade seja importante no exercício da atividade jurisdicional, não se deve descurar da ideia de eficiência, o que reflete em outros dois fatores: a qualidade e a alocação ótima de recursos.

Outro dilema apontado na concepção de eficiência judicial é a das garantias do devido processo legal, as quais não podem sucumbir frente à frenética busca pela eficiência. Assim, limitações ao direito ao contraditório, proibição do advogado no processo, restrição do direito das partes à produção de provas, falta de fundamentação mais acuradas das decisões racionais, entre outros; não podem ser elementos justificáveis para a procura da eficiência.

As medidas de defesa da eficiência para os TJs brasileiros não devem seguir apenas o trilho da celeridade da tramitação dos processos e da alocação eficiente de recursos, com sacrifícios das demais garantias processuais constitucionais.

Ilude-se quem pensa que a massificação dos litígios pode levar à eficiência do Poder Judiciário, no tratamento das decisões genéricas e semelhantes.

É necessário um sistema processual e de atividade jurisdicional que permita a produção de resultados justos, em tempo razoável e com o mínimo de recursos públicos.

A presente pesquisa se voltou apenas ao terceiro elemento, o qual passa a ser considerado na teoria da eficiência alocativa.

Quanto à produção de resultados justos e em tempo razoável, ainda representam objeto de estudo distinto da Teoria da Gestão Judicial, da Análise Econômica do Direito e da Jurimetria, os quais ainda procuram por uma solução teórica e prática.

\section{REFERÊNCIAS}

BANKER, R.D. CHARNES, A. COOPER, W.W. Some models for estimating technical scale inefficiencies in data envelopment analysis. Management Science, v. 30, n. 9, p. 1078$1092,1985$. 
CHARNES, Abraham; COOPER, William W.; RHODES, Edwardo L. Measuring the efficiency of decision-making units, European Journal of Operational Research, v. 2, p. 429-444. 1978.

COASE, Ronald H. The problem of social cost. Journal of Law and Economics, Chicago, vol. 3, n. 1, p. 1-44. 1960.

COOTER, R.; ULEN, T. Law and economics. $5^{\text {th }}$ ed. Boston, MA: Pearson, 2008.

HASTIE, R.; DAWES, R. Rational choice in an uncertain world: the psychology of judgment and decision making. London: Sage, 2001.

LOEVINGER, Lee. Jurimetrics: the methodology of legal inquiry, Jurimetrics: the methodology of legal inquiry. Law and contemporary problems, n. 28, p. 05-35, 1963.

MARINHO, R. Prática na teoria-aplicações da teoria dos jogos e da evolução aos negócios. São Paulo: Saraiva, 2005.

NUSDEO, Fábio. Curso de Economia: introdução ao direito econômico. 3. ed. São Paulo: Revista dos Tribunais, 2001.

POSNER, Richard A. Problemas da filosofia do direito. São Paulo: Martins Fontes, 2000. RIBEIRO, Márcia Carla Pereira. Racionalidade limitada. In: RIBEIRO, Márcia Carla Pereira;

KLEIN, Vinícius (coord.) O que é análise econômica do direito: uma introdução. Belo Horizonte: Fórum, 2011, p. 63-70.

RODRIGUES, V. Análise econômica do direito-uma introdução. Coimbra: Almedina, 2007.

SALAMA, Bruno M. O que é "Direito e Economia". In: TIMM, L. B. (Coord.). Direito e economia. Porto Alegre: Livraria do Advogado, 2008, p. 52-57.

SALDANHA, N. Ordem e hermenêutica. $2^{\text {a }}$ ed. Rio de Janeiro, Renovar, 2003. 